\title{
Logic of the Preface Paradox
}

\author{
DALE JACQUETTE \\ University of Bern
}

\begin{abstract}
The preface paradox is the apparent pragmatic inconsistency that occurs when the author of a book declares in its preface that despite believing that it is highly probable that everything the book maintains is true it is also highly probable that the book contains at least some errors. The preface paradox has often been presented as an example of a logically inconsistent belief that it is nevertheless rational to accept, supporting the suggestion that rationality has nothing immediately to do with avoiding formal logical inconsistency in one's beliefs. In contrast with complicated received solutions, I explain a simple method of avoiding inconsistency in preface paradox assertions by indexing the two claims to distinct probability or justification sources, referencing in the first case the conscientious efforts to eliminate errors and in the second case the chagrin of past experience in discovering previously unsuspected errors in published writings. The solution thereby helps preserve the concept of rationality as logical consistency of belief, and avoids the conclusion that the preface paradox proves that it is sometimes rational to accept logically inconsistent beliefs.
\end{abstract}

\section{The Preface Paradox}

The preface paradox is the apparent pragmatic inconsistency that occurs when an author declares in the preface of a book that, despite believing that everything the book asserts is true, it is also likely to contain at least some errors. The preface paradox is often presented as an example of a logically inconsistent belief that it is nevertheless rational to accept.

The author offers the book for publication on the assumption that it is errorfree, while acknowledging perhaps from past experience or a general understanding of human fallibility that there is a high probability, despite good intentions and conscientious efforts to avoid mistakes, that a document as large and complicated as a book is likely to include at least some minor inaccuracies, which it is only prudent to admit. Thus, it appears rational to accept a logically inconsistent belief or several mutually logically inconsistent beliefs, that the same book is probably error-free and probably contains at least some errors. It is rational to believe that a carefully competently written book will harbor no mistakes at the 
same time that it is also equally rational to believe that any book and hence the book in question probably contains at least some errors. ${ }^{1}$

\section{Problems in the Standard Solutions}

There are several stock reactions to the preface paradox in the philosophical literature, which it will be worthwhile briefly to recount. How should the preface paradox be interpreted? Is the contradiction deep and real, or only superficial and apparent? We can avoid inconsistency in the preface paradox altogether by suggesting a special way of understanding the claim that the book is probably error-free.

Perhaps what the author means in asserting that the book contains no mistakes is rather that it is hoped that the book contains no mistakes or that it is not known to contain any mistakes or that it is not known to contain any mistakes and that strenuous efforts have been made to discover and eliminate errors so that under the circumstances the book has been made as error-free as could possibly be managed from a practical point of view. If that or something like it is what the preface paradox author means in saying that the book is probably devoid of errors, then there is no logical difficulty, because there is o contradiction between such beliefs so construed and the belief that the book also probably contains at least some errors. Compare:

Original paradox statement:

1. The book is probably totally error-free.

2. The book nevertheless probably contains at least some errors.

Reinterpreted paradox with revision of first assertion:

1. The book is hoped to be totally error-free, and every effort has been made to make it so.

2. The book nevertheless probably contains at least some errors.

The trouble with this paraphrastic solution is that it does not do full justice to what the paradox author is rationally entitled to believe and to what the author of a carefully and competently written, vetted, checked, rechecked and proofed book manuscript might actually come to believe, rightly or wrongly, that the book is totally error-free, while still also rationally believing that there might be some mistakes that have crept in or gone undetected in spite of all the skill and preventive measures that have been taken.

Principia, 12(2) (2008), pp. 203-16. 
The proposal is unacceptable on its own terms, as a result, because it implausibly waters-down the degree to which the paradox author is rationally committed to believing that the book is actually error-free, while still acknowledging the possibility and even the high probability of latent error. The same is true of another obvious reinterpretive strategy involving an ambiguity in the scope of negation in the informal formulation of the paradox. There is no paradox, but also at best an inadequate statement of the author's belief in the probity of the book's content, if we rewrite the paradox in this form:

1. The book is not known to contain any errors.

2. The book nevertheless probably contains at least some errors.

As opposed to this alternative expression of the original paradoxical preface paradox:

1. The book is known not to contain any errors.

2. The book nevertheless probably contains at least some errors.

It is the latter set of statements that more accurately reflects the belief to which the paradox author is rationally committed, and rationally entitled to believe, particularly if knowledge is standardly defined as entailing defeasible justification rather than epistemic certainty. If knowledge also entails truth, however, then we are still in logical difficulty, where it is true because it is known that the book is error-free and yet probably contains at least some errors. What, then, are the other more promising possibilities for defusing the preface paradox?

One option, borrowing a page from the semantics of one style of paraconsistent logic, is to deny that rational belief is adjunctive. Another way to make the same point is to argue that belief generally or rational belief in particular is nonmonotonic, so that it does not follow from the fact that the paradox author rationally believes that the book is probably error-free, and that the paradox author rationally believes that the book nevertheless probably contains at least some errors, that therefore the author believes or rationally believes both that the book is probably error-free and that the book probably contains at least some errors. This is the approach to the problem defended by John N. Williams in his article, 'The Preface Paradox Dissolved'. Williams argues that the preface paradox demonstrates the possibility of rational inconsistent belief, but avoids logical antinomy by denying what he calls the 'conjunction principle', by which rational belief in multiple propositions implies a rational belief in their conjunction. Williams holds that if the conjunction principle is rejected, then the preface paradox beliefs can be seen as logically possible and hence nonparadoxical. ${ }^{2}$

Principia, 12(2) (2008), pp. 203-16. 
Again, the problem is that while the solution nominally avoids logical inconsistency, it pays too high a price in doing so. Although there are independent reasons for holding that some belief contexts are nonadjunctive and that rational belief in particular is nonmonotonic, the most plausible intuitively correct understanding of the preface paradox doxastic situation is that the paradox author does in fact rationally believe both propositions, and rationally believes their conjunction, expressible as a single proposition, that the book is probably totally error-free and that it probably contains at least some errors. It is also hard to see how eliminating adjunction or the conjunction principle in the preface paradox case by itself could be enough to avoid logical inconsistency. Is it not sufficiently paradoxical as things are for the book's author rationally to believe that the book is probably error-free and rationally to believe that the book nevertheless probably contains at least some errors, even if the author does not additionally believe that the book is probably error-free and probably contains at least some errors? Why are the two beliefs considered separately not already alarmingly paradoxical? How does refusing to infer as a single rational belief in the conjunction of the two beliefs do anything to neutralize the paradox that apparently inheres in the fact that the two mutually logically inconsistent propositions are individually rationally believed by the same doxastic agent with respect to the truth or correctness of the contents of the same book?

The preface paradox thereby appears to preserve its reputation as an example of a circumstance in which it is rational to believe something that is logically inconsistent, as Peter Klein in his essay, 'The Virtues of Inconsistency', among other epistemologists, have urged, or, as Douglas Odegard, in his paper, 'Locke and the Preface Paradox', suggests, that we are rationally justified in believing that at least one of our rationally justified beliefs is false. ${ }^{3}$

Finally, as we might expect, some philosophers and inductive logicians have recommended avoiding the putative logical inconsistency posed by the preface paradox by introducing sophisticated distinctions in the probability functions by which the probable truth of the book's being error-free versus the probable truth of the book's nevertheless containing at least some errors is roughly estimated or exactly calculated. A proposal of this kind is advanced by John L. Pollock, in his study, 'The Paradox of the Preface', distinguishing the concept of what he refers to as 'nomic probability' as the type of probability involved in statistical laws of nature related to belief acceptance rules that Pollock holds can be applied in a unified solution to the preface paradox, the lottery paradox, and the gambler's fallacy (Pollock 1986).

The lottery paradox is evidently closely related to the preface paradox in any

Principia, 12(2) (2008), pp. 203-16. 
case, so it is reassuring to suppose that there could exist a common solution to both of these pragmatic paradoxes. The lottery paradox is similar to the preface paradox, after all, in the sense that the lottery paradox also involves rational belief in a general probable truth, that it is highly improbable that any given lottery ticket will win, and an equally rational belief that one particular ticket, possibly the one the lottery participant has purchased or is considered purchasing, will definitely win. The connection between the iterative preface and lottery paradoxes is drawn along these lines by Paul K. Moser and Jeffrey Tlumak in their jointly authored paper, 'Two Paradoxes of Rational Acceptance', by Jonathan E. Adler, in 'Knowing, Betting and Cohering'. ${ }^{4}$ Bernard Linsky, in 'Factives, Blindspots and Some Paradoxes', following Roy A. Sorensen's metaphor in identifying commonalities in pragmatic and logical-semantic paradoxes, goes even further in linking the preface paradox not only to the lottery paradox, but also to Moore's paradox, in the sentence 'It is raining, but I do not believe it', and the surprise exam paradox, in which it appears both rational to believe that a surprise exam will be given on a previously unannounced day, and that, working backward incrementally from the last possible day for the event, the surprise exam cannot possibly occur on any day within the specified period of days. ${ }^{5}$

Pollock, in company with other inductive logicians, in this way can be seen to make progress in the right direction by elaborating a new theory of probability and inductive reasoning that is intuitively justifiable on its own terms and offers as justifiable on its own terms and offers as dividends the possibility of solving in a unified systematic way at least such puzzles about rational belief acceptance as the preface and lottery paradoxes.

\section{A Deflationary Resolution of the Preface Paradox}

What sustains interest in the preface paradox, to return to the problem at issue, is precisely the occasion it affords for exploring new theoretical territory, to develop new concepts, distinctions and principles, that may additionally be valuable for their own sake at the same time that they shed light on and may finally help to solve or avoid the paradoxes to which they owe their origin as a philosophical and technical logical or semantic response. All of this is so intrinsically commendable that one is reluctant to propose a solution to the paradox that does not require any of these interesting and potentially useful innovations - but that is exactly what I now propose to do.

The solution to the preface paradox that I shall now detail is simpler and for

Principia, 12 (2) (2008), pp. 203-16. 
that reason possibly less exciting than the standard methods that have emerged in ongoing investigations of the problem. Of course, I interpret what I see as the commonsense dimension of the solution as one of its chief merits, even though it means that nothing is added to the theory or apparatus of logic, cognitive psychology, or epistemology, by adopting its deflationary approach. I want to maintain, in fact, that the preface paradox is so easily and straightforwardly resolved by the technique I advocate that it is hard in retrospect to understand how anyone could have thought there was a genuine paradox to be seriously addressed in the first place, let alone to uphold the invention of new concepts, distinctions, logical or statistical syntax, or modifications of probability theory, the truth-functional logic of propositional connectives in nonadjunctive remedies to the preface paradox, or the like.

I perceive no defect in the simplicity and minimalism of the solution I am about to explain, but see these aspects on the contrary as important advantages. Still, I want to anticipate the disappointment that might ensue when it is seen with what facility the paradox is disarmed. The important asset that is gained by adopting this method, if it is correct - and I cannot resist adding at just this juncture that I believe that the solution is probably error-free but that after all it probably still contains some errors - is that it restores the intuitive concept, at least insofar as the preface paradox is concerned, that rationality does not circumstantially require or presuppose the possibility of accepting mutually logically inconsistent individually rationally justified beliefs. If the solution works, then it may additionally point the way to a similarly deflationary method of preserving the conceptual affinity between rationality and logically consistent belief, at least in the sense of continuing to regard doxastic logical consistency as a necessary even if not sufficient condition for rationality, and of the idea that reason and being reasonable has something to do with having logically consistent beliefs.

It will be useful in what follows to formalize the preface paradox and the proposed solution. We can symbolize a particular probability threshold value as ' $T$ ', the probability (function) ' $P$ ' of a proposition, ' $p$ ', that is believed, ' $B$ ', by a subject such as the paradox author, 's', together with the usual propositional connectives and comparatives for probability thresholds as follows:

$$
B_{s}(P(p)<T) \wedge B_{s}(P(p) \geq T)
$$

The formula states that subject $s$ believes that the probability of proposition $p$ is less than threshold value $T$ and subject $s$ believes that the probability of proposition $p$ is greater than or equal to that of threshold value $T$. Let $s$ be the preface paradox author and $p$ the proposition that the author's book contains

Principia, 12(2) (2008), pp. 203-16. 
at least some errors, and we have a relatively perspicuous formalization of the preface paradox.

The nonadjunctive solution is easily represented in this notation as the prohibition against inferring from the above conjunction an adjunctive conjunction involving a wide-scope application of the doxastic belief operator, $B$, as the proposition:

$$
B_{s}(P(p)<T \wedge P(p) \geq T)
$$

Disallowing the valid inference of (2) from (1) remains a questionable solution to the paradox for all the reasons we have already informally considered. It is nevertheless worthwhile to observe that the symbolism is sufficiently flexible to formalize the nonadjunctive proposal for dissolving the preface paradox. The notation also supports a formalization of the solution whereby the implicit scope of negation in the original paradox statement is disambiguated, in this way:

$$
B_{s}(P(p)<T) \wedge \neg B_{s}(P(p)<T)
$$

As opposed to:

$$
B_{s}(P(p)<T) \wedge B_{s} \neg(P(p)<T)
$$

We note that adjunction does not arise for proposition (3) as it does for (4), but that the negation scope solution is unsatisfactory for other reasons as an intuitively implausible and inaccurate expression of the paradox author's belief, and as such fails on grounds of inadequacy to the data.

It is important to distinguish any type of probability-related solution to the preface paradox from the effort to preserve logical consistency in the analysis by assigning different probability functions to the two beliefs, kept distinct or adjoined into one, in such a way that they do not add up to more than 1.0.6 Thus, there is no logical paradox if we rewrite the description of the author's beliefs in this form, choosing arbitrary but realistic probability values:

$$
B_{s}(P(p) \leq .90) \wedge B_{s}(P(p) \leq .10)
$$

The difficulty here as before is inadequacy to the data. There is no logical inconsistency provided that the paradox author believes to a degree of less than $90 \%$ probability that there is no error in the book although believing to a degree of less than $10 \%$ probability that the book after all contains at least some errors. All this would be fine, except for the fact that under the circumstances the paradox author believes to a strong degree $T$ of probability that the book is error-free while at the same believing to a possibly less strong but still sufficiently high degree of probability $T^{*}$ that the book nevertheless contains at least some errors,

Principia, 12(2) (2008), pp. 203-16. 
such that $T+T^{*}>1.0$, greater than $100 \%$. The paradox author, in other words, relatively strongly believes that the book is error-free at the same time as perhaps less but cumulatively still too strongly believes that the book after all contains at least some errors, as in propositions (1), (2), and (3). It is this version of the preface paradox for which a satisfactory solution is sought.

The alternative that I now want to present is to distinguish between alternative sources of probability assessments when these are clearly different in the two rational beliefs or compound conjoined rational belief in the probability that the book is error-free and that it nevertheless probably contains at least some errors. I recommend that we index these distinct sources, thereby syntactically precluding the appearance of genuine paradox and preserving logical consistency in the preface 'paradox'. The solution looks like this, which we can present as a modification of proposition (1):

$$
B_{s}\left(P^{e}(p)<T\right) \wedge B_{s}\left(P^{e^{\prime}}(p) \geq T\right)\left(e \neq e^{\prime}\right)
$$

Where $e \neq e^{\prime}$ as distinct evidence sources supporting the probability assessments in the original statements of rational belief in the paradox. Considerations of nonmonotonicity for belief or rational belief aside, in this symbolic framework we can unproblematically encourage adjunction or the conjunction principle without risk of logical inconsistency. As a logician would say, we can regard belief as closed under conjunction. The preface 'paradox' situation can now be presented as follows:

$$
B_{s}\left(P^{e}(p)<T \wedge P^{e^{\prime}}(p) \geq T\right)\left(e \neq e^{\prime}\right)
$$

For the solution to work, there must be a real basis in fact for distinguishing between evidence sources $e$ and $e^{\prime}$ on which the two otherwise conflicting probability assessments depend. This is no problem in the preface paradox, where intuitively the evidence that justifies the paradox author's belief that there is low probability of error in the book is different than the evidence that justifies belief in the high probability of there nevertheless existing at least some undetected error in the book. What justifies the author in believing that there is probably no error is all the hard conscientious work that has gone into writing, vetting, checking, rechecking, correcting and proofing the book, first-hand knowledge of the gauntlet of competent critics and refereeing process the book has survived, and the like. The evidence that supports the contrary beliefe that the book nevertheless probably contains at least some residual undiscovered errors is significantly different, consisting of general knowledge of human fallibility, experience

Principia, 12(2) (2008), pp. 203-16. 
with other books that may also have been issued with psychological certainty in their absence of error, but that later resulted in the author's chagrin, indicating the widespread occurrence of at least some errors in most if not all theoretical books, and related factors that enter into the belief's probability judgment that the book in the end is unlikely to be absolutely perfect.

There remains an interesting problem concerning the total evidence available for the author's belief in the preface paradox can be formulated in the above notation as the question of whether it is true that $B_{s}\left(P^{e+e^{\prime}}(p)\right)$ or $B_{s}\left(P^{e+e^{\prime}}(\neg p)\right)$, or whether, adjunctively and paradoxically, $B_{s}\left(P^{e+e^{\prime}}(p \wedge \neg p)\right)$. Of course, it is possible to consider a single probability function that collectively takes into account all of the evidence available to the preface author. On such an evidence-aggregative probability function, the preface paradox, as indicated, obviously returns. The point, however, is that if there is a legitimate reason for distinguishing conflicting evidence sources among the ostensibly incompatible assertions made in the author's preface, then there is no necessity for the preface to be interpreted as paradoxical, and hence no need to understand the preface paradox as implying that it can sometimes be rational to accept logically inconsistent beliefs. The total evidence available to the author does not ineluctably force the paradox, provided that there is a sufficiently good reason for the author to believe either that $P^{e}(p)>P^{e^{\prime}}(\neg p)$ or that $P^{e}(p)<P^{e^{\prime}}(\neg p)$.

The question, in other words, can equivalently be put as to which belief the author, given access to the total evidence available under the circumstances should rationally bet on as being true. If it should turn out, perhaps astonishingly, that $P^{e}(p)=P^{e^{\prime}}(\neg p)$, then in an adjunctive environment, we would be compelled to infer that $B_{s}\left(P^{e+e^{\prime}}(p \wedge \neg p)\right)$, and would then need to consider a complex solution involving nonadjunction, nonmonotonicity, paraconsistency, or the like. From a practical perspective, on the other hand, it is hard to imagine that distinct evidence sources in such a case would ever precisely coincide or that we would ever need to assume that they precisely coincide. We should expect on the contrary that ordinarily the evidence that there is at least some unnoticed error in the book trumps the evidence that the book is $100 \%$ error-free. This is arguably what any seasoned experience of the world and of the book publishing trade in particular should lead a prudent author to believe. A priori, moreover, it appears more likely for some, at least one, error, however minor or miniscule, to occur, since there need only be one in a large text, than for none whatsoever to occur over the same number of possible occurrences in the same size text.

We can say, then, that although an author who remarkably has precisely the same justification for both believing that the book is error-laden and error-free

Principia, 12(2) (2008), pp. 203-16. 
happens under those accidental epistemic circumstances to fall into logical inconsistency if not irrationality in a classical logical framework, the problem is not generalizable as a paradox for every situation in which an author is justified in asserting both that a book is error-laden and error-free. There is nothing at all irrational about such a statement considered in and of itself, unless it happens against all odds and in the most unexpected of empirical situations that the evidence supporting both beliefs turns out to be precisely identical.

\section{Distinct Evidence Sources in Probability Assessments}

Probabilistic qualifications that derive from and depend on different evidence bases need to be syntactically distinguished in any case; otherwise, logical difficulties of a much more general type inevitably ensue. Thus, it is true that it is highly probable that the next prime minister will be a conservative, given that the previous prime minister was a liberal, together with the long-running history of past elections that justifies accepting the high probability of an alteration from liberal to conservative and conservative to liberal leadership in alternate election periods. It may also be true, nonetheless, that it is not highly probable that the next prime minister will be a conservative, given that the empirical evidence accumulating from ongoing exit polls supports the opposite projected election outcome.

If we do not distinguish syntactically between the probabilistic qualifications of these two propositions relative to distinct relevant probability sources, then we can classically deductively prove anything we like, such as the existence (or nonexistence) of God:

Argument G:

1. It is highly probable that the next prime minister will be a conservative.

2. It is not the case that it is highly probable that the next prime minister will be a conservative.

\section{Therefore, God exists!}

Whereas, the evident fallacy in argument $G$ is to equivocate on the two distinct senses in which assumptions (1) and (2) are probabilistically qualified. We avoid the superficial paradox in argument $G$ by making these senses explicit, indexing the probabilistic qualifications of the premises so as to preclude syntactical

Principia, 12(2) (2008), pp. 203-16. 
inconsistency of the two stipulatively true assumptions by which the inference is rendered sound and its conclusion paradoxically true. We then write:

Argument $\mathrm{G}^{*}$ :

1. It is highly probable ${ }^{e}$ that the next prime minister will be a conservative.

2. It is not the case that it is highly probable $e^{e^{\prime}}$ that the next prime minister will be a conservative. $\left(e \neq e^{\prime}\right)$

\section{Therefore, God exists!}

(INVALID!)

We can and should make the same reformulation in the preface paradox, as we have indicated, with the same effect in blocking the paradoxical inference in the original statement of the problem, making explicit the fallacy of equivocation that otherwise arises, so as to invalidate the implication of logical inconsistency. The revision of paradox statements (1) and (2) as (6) and (7), like the revision of argument $G$ as $G^{*}$, marks the distinction between different relevant probability sources in the two conflicting belief components of the preface paradox.

\section{Logical Consistency and the Concept of Rationality}

What does the proposed solution imply for the concept of rationality? The important implication is that the preface paradox need not stand as an example in which it is rational to accept logically inconsistent beliefs. The solution is low maintenance in its conclusion that there is no real preface paradox to solve in the first place, and that avoiding the paradox need not involve modifying the standard propositional connectives or adjunction principles for rational belief, or revising probability functions for the truth of propositions. All we need do is recognize what is clearly true and needs to be acknowledged anyway: that distinct probability assessments often involve and depend on distinct evidence sources. It is sufficient to avoid logical inconsistency in the paradox for these distinct evidence sources to be explicitly indexed or otherwise indicated, whether we are considering the paradox formally or informally. If the solution is accepted, it removes an obstacle to upholding the default interpretation whereby rationality is in part at least dependent on logical consistency, that it is irrational to accept logically inconsistent or contradictory beliefs, and that logical consistency is a necessary if not sufficient requirement of rationality. ${ }^{?}$

Principia, 12(2) (2008), pp. 203-16. 


\section{References}

Adler, J. E. 1986. Knowing, Betting and Cohering. Philosophical Topics 14: 243-57.

Feher, M. 1990. Fallibility (Comments on P. Klein's “The Virtues of Inconsistency”). Epistemologia 13: 337-44.

Huffman, R. 1973. The Paradox of the Preface Again. Mind 82: 441.

Klein, P. 1985. The Virtues of Inconsistency. The Monist 62: 105-35.

—. 1986. Immune Belief Systems. Philosophical Topics 14: 259-80.

Lacey, A. R. 1970. The Paradox of the Preface. Mind 79: 614-5.

Linsky, B. 1986. Factives, Blindspots and Some Paradoxes. Analysis 46: 10-15.

Makinson, D. C. 1965. The Paradox of the Preface. The Philosophical Quarterly 25: 2057.

Moser, P. K. \& Tlumak, J. 1985. Two Paradoxes of Rational Acceptance. Erkenntnis 23: $117-42$.

New, C. G. 1978. A Note on the Paradox of the Preface. The Philosophical Quarterly 28: 341-44.

Odegard, D. 1994. Locke and the Preface Paradox. Locke Newsletter 25: 29-40.

Pollock, J. L. 1986. The Paradox of the Preface. Philosophy of Science 53: 246-58.

Sorensen, R. A. 1988. Blindspots. Oxford: The Clarendon Press.

—. 1998. Yablo's Paradox and Kindred Infinite Liars. Mind 107: 137-55.

Williams, J. N. 1987. The Preface Paradox Dissolved. Theoria 53: 121-40.

\section{Keywords}

Belief, epistemology, induction, logic, preface paradox, probability theory, rationality.

Dale Jacquette

Institut für Philosophie

Länggassstraße 49a

CH-3000 Bern 9

Switzerland

dale.jacquette@philo.unibe.ch

\section{Resumo}

O paradoxo do prefácio é a aparente inconsistência pragmática que ocorre quando o autor de um livro declara em seu prefácio que, apesar de acreditar que seja altamente provável que tudo o que o livro afirma seja verdadeiro, é também altamente provável que o livro contenha pelo menos alguns erros. $\mathrm{O}$

Principia, 12(2) (2008), pp. 203-16. 
paradoxo do prefácio tem sido freqüentemente apresentado como exemplo de uma crença localmente inconsistente cuja aceitação, não obstante, é racional, dando suporte à sugestão de que racionalidade não tem nada imediatamente a ver com evitar inconsistências lógicas formais nas crenças de alguém. Ao contrário das complicadas soluções apresentadas, exponho um método simples de evitar a inconsistência em asserções do paradoxo do prefácio indexando as duas afirmações a fontes distintas de probabilidade ou justificação, referenciando no primeiro caso os esforços conscientes para eliminar erros e no segundo o desgosto de experiências passadas ao descobrir erros previamente insuspeitos em escritos publicados. A solução com isso ajuda a preservar o conceito de racionalidade como consistência lógica geralmente determina que o paradoxo do prefácio não estabelece a conclusão de que seja racional aceitar crenças logicamente inconsistentes.

\section{Palavras-chave}

Crença, epistemologia, indução, lógica, paradoxo do prefácio, teoria da probabilidade, rationalidade.

\section{Notes}

${ }^{1}$ An early statement of the paradox is offered by D. C. Makinson (Makinson 1965).

2 See Williams 1987. Williams distinguishes between 'inconsistent' and 'contradictory' beliefs in the preface paradox, and argues that the conjunction principle contributes to failures to observe the distinction in categorizations of the paradox situation as irrational. ${ }^{3}$ Klein 1985. See also Klein 1986, Odegard 1994. A criticism of Klein is offered by Feher 1990.

${ }^{4}$ Moser and Tlumak 1985; Adler 1986. See also New 1978.

${ }^{5}$ Linsky 1986. The blindspots metaphor to which Linsky appeals originates with Roy A. Sorensen (1988). See also Sorensen 1998. Analogies between the preface paradox in its iterative formulations (there is no error on the first page, second page, etc., but there is probably an error somewhere in the book as a whole) and the lottery paradox, are emphasized by several of these commentators. The proposed resolution covers both versions of the paradox when, regardless of how the proposition is supported, whether incrementally, sentence by sentence or page by page, or in one lump sum evaluation, provided that in either case the conclusion is reached that the book in its entirety as a whole both to a certain degree of probability contains no errors and to a certain degree of probability contains at least some errors, where the combined total probability of both probability judgments is $>1.0$.

Principia, 12(2) (2008), pp. 203-16. 
${ }^{6}$ A solution to the preface paradox of this kind is proposed by A. R. Lacey (1970). Lacey refers to Robert Huffman's 1968 Mind article with the same title. Huffman replies to Lacey in (1973).

7 This essay was presented at the Conference on Rationality, Bled, Slovenia, June 3-8, 2002, and at the American Philosophical Association, Association for Informal Logic and Critical Thinking, San Francisco, CA, March 27-30, 2003.

Principia, 12(2) (2008), pp. 203-16. 